\title{
Simulation of wind driven ventilative cooling systems for an apartment building in Beijing and Shanghai
}

\author{
G. Carrilho da Graça, Q. Chen*, L.R. Glicksman, L.K. Norford \\ Building Technology Program, Massachusetts Institute of Technology \\ 77 Massachusetts Avenue, Cambridge, MA 02139-4307, U.S.A. \\ "Phone: (617) 253-7714, Fax: (617) 253-6152, Email: qchen@mit.edu
}

\begin{abstract}
This paper presents a performance evaluation of two passive cooling strategies, daytime ventilation and night cooling, for a generic, six-story suburban apartment building in Beijing and Shanghai. The investigation uses a coupled, transient simulation approach to model heat transfer and airflow in the apartments. Wind driven ventilation is simulated using computational fluid dynamics (CFD). Occupant thermal comfort is accessed using Fanger's comfort model. The results show that night cooling is superior to daytime ventilation. Night cooling may replace air-conditioning systems for a significant part of the cooling season in Beijing, but with a high condensation risk. For Shanghai, neither of the two passive cooling strategies can be considered successful.
\end{abstract}

Keywords: Natural ventilation, CFD, Energy analysis

\section{Introduction}

Throughout the entire world, buildings are major consumers of energy and major sources of greenhouse gas emissions. In China, buildings consume $17 \%$ of the total energy spent in the country. This percentage is increasing every year. Future projections indicate that China will become the largest single source of greenhouse gas emissions in the next century. China contains seven out of the ten most polluted cities in the world. This is mainly due to coal combustion plants which produce energy for buildings and industry. In order to reduce pollution and greenhouse gas emissions, it is important to develop energy-efficient building designs and technologies that can be applied in China.

Beijing and Shanghai, the two largest cities in China, are located in different climatic regions. The climate in Beijing is colder in the winter and less humid, while Shanghai is particularly hot and humid in the summer. In both cities, buildings generally need constant air-conditioning in the summer in order to remove heat gains and achieve acceptable levels of indoor thermal comfort. In many situations, passive cooling systems are a suitable alternative to air-conditioning. Passive cooling systems transfer heat from the building into the atmosphere or ground with little or no use of mechanical means. These systems can be grouped into five main types [1]:

- Daytime Comfort Ventilation (Daytime Ventilative Cooling) is the most commonly used passive cooling system. Outdoor air flows through the building during the day, directly removing the heat gains (see Fig. 1(a)). The system can improve the occupant's thermal comfort by increasing convective and evaporative heat transfer, and by decreasing the indoor air temperature. The maximum indoor air velocity should not exceed $2 \mathrm{~m} / \mathrm{s}$ [2]. If the outside 
temperature is high, the indoor air temperature will generally be too high to be acceptable to the occupants.

- $\quad$ Night Cooling (Nighttime Ventilative Cooling) uses cold outdoor air during the night to cool the building's thermal mass (building internal partitions and structure). The thermal mass functions as a heat sink during the day, absorbing the internal heat gains. Figs. 1(b) and 1(c) show the operation principle of night cooling. In order to reduce the heat gains due to ventilation during the day, the windows should be kept closed. Often a ceiling fan is used to enhance indoor air circulation and increase the heat exchange between the occupants and the thermal mass. The lower the outdoor air temperature during the night, the more effective the night cooling system is. This system works better for a climate with a minimum temperature below $22^{\circ} \mathrm{C}$ during the night.

- Evaporative Cooling reduces the temperature of the ventilation air by water evaporation. With a direct evaporative cooling system, the evaporation process decreases the air temperature while increasing its humidity. Indirect systems provide cooled fluid to chill the indoor air through a heat exchanger. Evaporative cooling systems are only effective in dry climates.

- $\quad$ Radiative Cooling removes heat from the building's external elements through long-wave radiative exchange with the sky at night. The cooled building element then absorbs part of the heat gains during day. The system works better in regions with a clear nighttime sky and buildings with large exterior surfaces.

- Ground Coupled Cooling uses the ground as a heat sink. The ground temperature is generally lower than the indoor temperatures in summer. The building heat gains are transferred to the ground using a mechanical system.

In theory, almost all of the above mentioned passive cooling systems could be applied to Beijing and Shanghai. In these cities, most residential buildings are apartments (medium to high-rise). Since the climate in both cities is hot and often humid, , the use of evaporative cooling is limited by the rather high humidity levels encountered in these climates. In these cities, the humidity rises to above $70 \%$ on most days, reaching peaks of above $95 \%$ during humidity waves. The application of a radiative cooling system to apartment buildings is very challenging, because the system requires a large building surface to radiate heat to the sky. The system is only feasible in low-density, low-rise buildings. Ground coupled passive cooling for medium to high-rise buildings can be a rather expensive option due to the high construction costs and the need for a heat exchanger system to transfer heat into the ground.

Therefore, daytime ventilation and night cooling are the possible choices. One obvious problem with the two systems is their dependence on the ventilation level of the building. Without adequate ventilation, the two systems will not work at all. The ventilation levels depend not only on building geometry, but also on the microclimate surrounding the building. When compared to air-conditioning, ventilative cooling systems consume less energy, require less maintenance, have lower first-costs, and are environmentally friendly. This paper reports our studies on the effectiveness of the daytime ventilation and night cooling systems in Beijing and Shanghai. 


\section{Research approach}

\subsection{Numerical models}

The study of wind driven passive cooling systems requires accurate modeling of the building thermal response to the outdoor climate conditions and internal heat gains. The thermal response, in conjunction with ventilation models, can determine the indoor air temperature, relative humidity, air velocity, and environmental temperature provided by the ventilation systems. These parameters determine the thermal comfort in the building.

Kammerud et al. [3] used a building thermal analysis program (BLAST) to study the effect of using a night cooling strategy on the cooling load in a typical house for several locations in the U.S. He cited two main problems encountered in his work: difficulty in estimating the naturally driven airflow through the building, and an incorrect estimation of heat transfer coefficients. For wind driven flows in single story apartment units, forced convection often dominates the heat transfer process. In these cases the heat transfer coefficients depend on the air velocity near the walls and other partition elements. In order to address these two problems, the present investigation uses a combined model of computational fluid dynamics (CFD) and building thermal analysis. Using a simplified building geometry, the CFD program is used to calculate wind driven airflow through the building for a set of wind velocities and directions. The CFD results are then processed to calculate air velocity distributions near the walls, allowing for accurate prediction of the convective heat transfer coefficients. An experimental correlation for naturally ventilated buildings [4] is used to calculate the convective heat transfer coefficients as a function of the air velocity near the walls. These coefficients are used as boundary conditions in the building thermal analysis. This approach couples building thermal analysis with an isothermal CFD simulation, avoiding the heavy computational burden of using CFD for different air and indoor surface temperatures. This may be acceptable for comfort and thermal analysis because the temperature distribution in a building with wind driven ventilation is rather uniform (due to the high airflow rates). Fig. 2 shows the structure of the coupled model. Finally, the results of the airflow simulation and the thermal analysis, such as indoor air velocity, temperature, relative humidity, and environmental temperature, can be used to determine the thermal comfort in the building using the thermal comfort model [5].

The performance of a wind driven cooling system is directly dependent on the magnitude of the airflow in the building and the heat removal by convection. Hence, accurate modeling of the wind driven airflow is important. In the last twenty years, extensive work has been done in applying CFD to airflow in and around buildings. Comparisons of CFD simulations with wind tunnel experiments [6-7] found a good agreement between numerical and experimental results. However, Murakami et al. [8] showed some of the limitations of the $k-\varepsilon$ model when compared to rigorous laboratory measurements and results from a more precise turbulence modeling technique known as large eddy simulation. Some assumptions used in the k- $\varepsilon$ model, such as isotropic turbulence, are not strictly applicable to flows in and around buildings. Since large eddy simulation demands high computing time at present, the 
CFD program used in this investigation [9] uses the $\mathrm{k}-\varepsilon$ turbulence model. It is relevant to note that, the present study uses other approximations that can potentially have higher effects in the result such as: the use of non site specific weather data and the use of unfurnished apartment units in the simulations.

If the CFD program is applied to calculate simultaneously indoor and outdoor airflow there is a need for a fast computer with a large memory. Therefore, it is a common practice to separate indoor airflow simulation from outdoor airflow simulation. However, experimental work by Straaten [10] shows that whenever the total area of the ventilation apertures in the building façade exceeds $20 \%$ of the total area, this uncoupled approach is not adequate. Many buildings with natural ventilation features have an aperture area of more than $20 \%$. This makes a coupled indoor-outdoor airflow simulation necessary. If more than one building is involved in the simulation, the approximation method proposed by Allocca et al. [11] should be used in order to reduce computing time.

The experimental findings by Straaten are a direct consequence of momentum conservation. Since air is flowing through the highly porous cross-ventilated building, the amount of deflected impinging flow is reduced. Due to the non-negligible amount of air flowing across the building, the pressure coefficients on the windward side tend to be lower than those obtained in a closed model [12]. The flow domain should then be sufficiently large to reproduce realistic external flow conditions. A survey on the literature and a set of preliminary simulations suggested that the distance between the upwind boundary and the building should be at least $150 \%$ of the building height. Fig. 3 shows the flow domain and the numerical discretization grid. Inside the building the average grid dimension is $0.5 \mathrm{~m}$, outside; the grid size increases in proportion to the distance from the building facade. The number of grid points used in this study is 74 in $\mathrm{X}, 58$ in $\mathrm{Y}$ and 45 in the $\mathrm{Z}$ axis, an approximate total of $2 \times 10^{6}$ grid points.

In the atmospheric boundary layer, mean wind velocity increases with height as a consequence of friction between the layer of moving air and the ground. The size and slope of the boundary layer depend on the roughness of the ground surface. An exponential profile ASHRAE [13]. When modeling a building site, an assumption must be made on what is the prevailing type of wind profile in the area. In the present case, an isolated apartment building in an urban area, values characteristic of an urban/suburban area are used. The exponential urban wind profile was dicretized using ten inlets in order to keep the discretization error below 5\% for any point in the z-axis.

The value of the inflow turbulent kinetic energy is one of the boundary conditions that must be provided to the turbulence model. It influences the calculated flow field through the effective turbulent viscosity parameter. Whenever mechanically generated turbulence prevails in the lower part of the atmospheric boundary layer the turbulent intensity can be adequately modeled as constant (Panofsky [14]). In an urban area with wind, this approximation is adequate, it fails when there is no wind and high buoyancy forces are present (the other possible sourceof atmospheric boundary layer turbulence). The value used for the inlet turbulence intensity was $16 \%$. This value is similar to the one adopted by Haghighat [15] and close to the one measured by Etheridge [16]. 
Each CFD airflow simulation took approximately 18 hours on a $450 \mathrm{MHz}$ Pentium II PC. The coupled model uses a fixed airflow pattern for each outside wind direction and velocity, independent of the thermal conditions. This approximation is acceptable because the thermal buoyancy forces are smaller than the inertial forces that occur in cross ventilation. The validity of this approximation can be accessed by calculating the Archimedes number, Ar, for the flow inside the building:

$$
\mathrm{Ar}=\mathrm{gL} \Delta \mathrm{T} /\left(\mathrm{V}^{2} \mathrm{~T}\right)
$$

where $\mathrm{g}$ is the gravity acceleration, $\mathrm{L}$ is the typical length scale (such as room height), $\Delta \mathrm{T}$ is the typical average temperature difference between the surface and the air, and V is the typical velocity of the external flow. Ar is a ratio of the buoyancy forces (the numerator) over the inertial forces (the denominator). In the present study, Ar varies from 0.3 to 0.03 when the wind changes from 1 to $3 \mathrm{~m} / \mathrm{s}$ with $\Delta \mathrm{T}=3 \mathrm{~K}$ and $\mathrm{L}=2.7 \mathrm{~m}$. The approximation is better for high wind velocities.

With this approximation, it is possible to pre-run the flow simulations creating a database of flow cases that is accessed according to outside weather conditions. The files containing the results of the simulations where processed to obtain a set of indoor flow parameters necessary for the coupled model (fig. 2):

- $\quad$ Airflow rates for each of the four rooms.

- Average air velocity in the occupied area of the living room (for the calculation of convective cooling of the occupants, an input to Fanger's comfort model [5]).

- Average air velocities in the grid point adjacent to each wall surface of the apartment (indoor and outdoor).

The thermal response of the building was calculated by solving the heat transfer equation with an explicit finite differencing method [17]. Heat conduction through the building enclosure and in the internal partitions was treated one-dimensionally. The differencing method divided the walls into $15 \mathrm{~mm}$ layers. Radiative heat transfer was calculated using the radiosity method [17]. The model calculated short wave and infrared radiation separately. A detailed description of the heat transfer model and coupled simulation procedure can be found in Carrilho da Graça [14].

\subsection{Control strategies}

In order to compare the performance of the two passive cooling systems, it is necessary to implement control strategies in the computer simulation. Passive ventilation systems can be controlled in several ways: automatic, manual or a combination of the two. For the case we are studied, manual control is expected. Therefore, in order to compare the performance of the two passive cooling strategies it is necessary to implement user manual control into the computer simulation. For this purpose we considered that when using these two strategies users will regulate the opening of windows according to the following set of rules based on common sense actions: 
- If the outside air is colder than the inside air, and the apartment temperature is not too cold, such as below $24^{\circ} \mathrm{C}$, the building occupants will open the windows.

- If at the end of the day, the indoor temperature is below $24^{\circ} \mathrm{C}$, the occupants will not open the windows during the following night.

- For daytime ventilation, if the apartment is warm (above $28^{\circ} \mathrm{C}$ ), the occupants will open the windows to increase convection.

- $\quad$ During the day the users turn on ceiling fans.

Figs. 4 and 5 present in more detail the control system diagram for the night cooling and daytime comfort ventilation systems.

\section{Case setup}

The left part of Fig. 5 shows the north-south oriented building that was studied. It is a six-story apartment building with ten units (two units per floor) in which the ground floor is used for storage spaces. The building is considered to be located in an open suburban area. The right part of Fig. 6 shows the internal layout of an apartment unit in the building. Each unit has three bedrooms and a total floor area of $115 \mathrm{~m}^{2}$. The surfaces in dark gray represent the external walls and floors, and those in light gray represent the internal partitions. Access to the apartments is through an external corridor on the north side of the units (located in the upper part in the drawing). On the south side of each living room, there is an external balcony.

Several design features make this building suitable for cross ventilation. The separation of the living room from the three bedrooms allows for high ventilation rates in the living room during the night when the occupants are in the bedrooms. This arrangement enhances nighttime heat release from the living room surfaces. Another feature that increases cross-ventilation is the large apertures above the internal doors. These apertures allow for air to flow through the bedrooms even when the doors are closed. External shading is used in all the south windows to block the summer sun. The balcony of the living room upstairs provides shading for the living room window directly below it. When the apartment is in a maximum ventilation mode, both the balcony window and the northern windows in the living room are fully open. During the day, ceiling fans are used in the apartment to enhance convective heat transfer between the thermal mass and the occupants.

The windows are double-glazed with an aluminum frame that has no thermal break (DSA, 2.4mm glass). In accordance with common Chinese construction standards the model uses an infiltration rate of $1.5 \mathrm{ACH}$. The flooring material is ceramic tile. Fifty percent of the living room windows are covered by light venetian blinds with a shading coefficient of 0.33 . Table 1 further defines the cases studied. The internal gains, shown in Table 2, were estimated according to ASHRAE recommendations [13]. The present study did not perform a sensitivity study on the internal heat gains. The metabolic rate for each occupant is 0.8 met (for comfort calculations 1.2 met is used, see section 1.2), which for an exposed area of $1.8 \mathrm{~m}^{2}$ gives a heat gain of $85 \mathrm{~W}$ per occupant. According to ASHRAE recommendations [13], this heat gain is considered to be $70 \%$ radiative and $30 \%$ convective. It is considered that the occupants use light summer clothes, corresponding to a clothing resistance factor of 0.5 clo. 
In order to better evaluate the performance of the two passive cooling systems, a reference case is used. The reference case, as shown in Table 1 , has a reasonable amount of thermal mass. This agrees well with most current buildings in Beijing and Shanghai. Since the majority of the existing buildings and current designs do not use passive cooling strategies, this study estimates that in conventional buildings (represented by the reference case), the flow rate due to natural ventilation is $30 \%$ of that in our designs. The reference case did not use a ceiling fan. The results are also compared with the thermal comfort under the ambient air temperature and humidity (the outside case). The daytime ventilation case has only $20 \%$ of windows open window during the night, as opposed to $100 \%$ for the night cooling case. Our calculation did not consider presence of screens and their air resistance. During the daytime, cross ventilation is used whenever the indoor air temperature is higher than the outside air temperature. The daytime ventilation case uses a lighter structure than the other cases.

\section{Results}

In a passive cooling system, outside air temperature and humidity are crucial to the system performance. Table 3 shows a few important climatic parameters for Beijing and Shanghai in the warmer months of the year (from May to September). The first column shows the number of days with maximum air temperature above $30^{\circ} \mathrm{C}$. These are the days when, for a properly designed building, cooling may be needed. The second column shows the average temperature variation between day and night during these days. This parameter is important for the night cooling system. A large temperature variation will make night cooling more effective, because the low temperature airflow during the night will remove more heat from the building thermal mass. The last two columns show the average wind speed during the day, which is important for the daytime ventilation system, and during the night, which is important for night cooling. Compared to Beijing, Shanghai has a warmer climate with a higher humidity and lower temperature variation. It is more challenging to successfully apply passive cooling systems in Shanghai.

The present analysis uses two criteria to evaluate the passive cooling systems:

- The number of hours of thermal discomfort during the warm season (from May 1st to September 30th), calculated using Fanger's thermal comfort model [5].

- The maximum indoor air temperature for each day during the warm season.

A supplementary criterion, used only for the warmest days of the season (maximum $\mathrm{T}_{\text {out }}>30^{\circ} \mathrm{C}$ ), is the average difference between the maximum indoor and outdoor air temperatures.

The following sections discuss the performance of the two passive cooling systems in Beijing and Shanghai and compare them with the two reference cases mentioned above. 


\subsection{Performance of the passive cooling systems in Beijing}

Fig. 7 shows the percentage of discomfort hours in the warm season for the five cases analyzed. The left figure is for whole day and the right figure is from 7:00 to 24:00. The results show that, as expected, about $95 \%$ of the discomfort hours occur in the period between 7:00 and 24:00. The dark gray bars are the results for the two passive ventilation strategies. The results show that night cooling is effective in Beijing. There are only 330 discomfort hours $(9 \%$ of the total number of hours in the warm season). When compared to the reference case, there is a $57 \%$ reduction in the number of discomfort hours (a reduction of 437 hours of thermal discomfort). Daytime ventilation improves the thermal comfort slightly. The number of discomfort hours when using daytime ventilation is close to that of ambient air temperature. This is a consequence of the fact that as air moves through the apartment during the day, it not only removes the heat gains (a positive process) but it also heats the walls of the apartment (a negative process). The case labeled NC+DV is a combination of the two ventilation strategies. It uses the night cooling control strategy during the night and the daytime ventilation control strategy during the day. For this case the results are much better than the reference case, but still not as good as the night cooling case.

Fig. 8 shows the temperature evolution over a two and half day period in Beijing for night cooling. For this strategy, during the night period, the indoor air temperature is close to outdoor except when the wind velocity is low. In these low wind periods the indoor temperature approaches the wall temperature, this is visible in the sharp peaks present in the indoor temperature profile in the second and third night periods. Fig. 9 shows the temperature evolution over a similar period in Beijing for daytime comfort ventilation. One noticeable difference when comparing with the previous figure is the fact that the indoor temperature closely follows the outdoor temperature. The effect of the lower thermal mass of this case is visible in the larger variations in the wall temperature.

Figs. 10 and 11 show the maximum indoor and outdoor air temperatures in the warm season with the two cooling strategies. The air temperature in the living room with night cooling is noticeably lower than the outside air temperature. The maximum air temperature in the living room during the season is $31.6^{\circ} \mathrm{C}$. On average, the indoor air temperature is $3.9 \mathrm{~K}$ cooler than the outdoor temperature. With daytime ventilation, the windows are open whenever the air temperature in the living room is higher than the outside air temperature. Therefore, the maximum indoor temperature is very similar to the outside - it can even be higher than the outside. The simulation shows that the maximum indoor air temperature can be higher than $34^{\circ} \mathrm{C}$ in eight days. The results show that night cooling is superior to daytime ventilation in Beijing.

\subsection{Performance of the Passive Cooling Systems in Shanghai}

Shanghai is warm and humid and has a very small daily-temperature variation, as shown in Table 3. The climate conditions indicate the challenges in applying the two passive cooling systems there. Nevertheless, Fig. 11 shows that the two passive cooling systems can help to achieve a better comfort level (when compared with the two reference cases). Night cooling is the best among the cases studied, but the improvement is not substantial when compared with daytime ventilation or the 
reference cases. This is due to the small daily-temperature variation, although the maximum outdoor air temperature is almost the same as that in Beijing. The small temperature variation outdoors does not allow for significant cooling of the building thermal mass.

Even with night cooling, the maximum indoor air temperature can be as high as $34.9^{\circ} \mathrm{C}$. On average, night cooling can only lower the room air temperature by 0.9 $\mathrm{K}$, as shown in Fig. 13. There are 29 days during the warm season with a maximum day temperature of above $32^{\circ} \mathrm{C}$, and 32 days with a maximum day temperature between 30 and $32^{\circ} \mathrm{C}$. The indoor air is too hot to be acceptable to the occupants.

The results show that using the two passive cooling systems alone during the warm season in Shanghai is not sufficient to provide comfortable indoor thermal conditions.

\section{Discussion of condensation risk}

The climate factors presented in table 3 clearly display the fact that the Shanghai climate is hot and humid. In this type of climate, the risk of condensation is high. This risk can be severe when using night cooling, because the high thermal mass surface temperatures are low, increasing the condensation risk. Although the highest relative humidity occurs during the night hours, the lowest dewpoint air temperature occurs in the daytime. During the day, air that infiltrates from the outside (this study uses 1.5 $\mathrm{ACH}$ ) comes in contact with the cool surfaces of the thermal mass elements, and condensation can occur. This is because during the day, the temperature difference between inside and outside can be as high as $6 \mathrm{~K}$.

Our calculations show that in Beijing, condensation can occur on the surfaces of the high thermal mass elements during 60 hours of the entire warm season (when using the night cooling system). With daytime ventilation, the condensation risk is much lower. This is because night cooling leads to much lower surface temperatures. Surprisingly, condensation is not very significant (it might occur in only 8 hours) in Shanghai, although the relative humidity of the outside air is much higher than that in Beijing. The reason is that the air temperature at night is high in Shanghai. The high temperature does not cool the building thermal mass very much. Therefore, the surface temperatures are higher than the outside air dewpoint temperature.

\section{Conclusions}

This paper evaluates the performance of two passive cooling systems, daytime ventilation and night cooling, for a generic, six-story apartment building in Beijing and Shanghai. The investigation introduced a new, detailed simulation method to simulate cross natural ventilation and to analyze the thermal response of the apartment building.

The results show that night cooling is superior to daytime ventilation in both Beijing and Shanghai. Night cooling may replace air conditioning systems for a major part of the cooling season in Beijing, about $90 \%$ of the time. On average, the maximum indoor air temperature is $3.9 \mathrm{~K}$ cooler than the maximum outdoor air temperature in Beijing, with night cooling. Daytime ventilation helps to provide a 
better comfort level indoors, but the improvement is not very significant. The two passive cooling systems cannot work effectively in Shanghai, since comfort conditions are only assured in $66 \%$ of the warm period. This is due to the small dailytemperature variation and high air temperature and humidity in Shanghai.

Condensation can be a problem in Beijing when using night cooling. The study found that condensation might occur for 60 hours during the warm season. Condensation is negligible in Shanghai, although it is a hot and humid climate.

\section{Acknowledgments}

The authors would like to thank the V. Kahn-Rasmussen Foundation (through the Alliance for Global Sustainability) and the Fundação para a Ciência e Tecnologia (Lisbon, Portugal) for supporting the research.

\section{References}

[1] B. Givoni, Passive and Low Energy Cooling of Buildings. Van Nostrand Reinhold, New York, 1994.

[2] B. Givoni, Climate Considerations in Building and Urban Design. Van Nostrand Reinhold, New York, 1998.

[3] R. Kammerud, E. Ceballos, B. Curtis, W. Place, B. Anderson, Ventilation cooling of residential buildings, ASHRAE Transactions, (1984) 95(2), 226251.

[4] S. Chandra, A.A. Kerestecioglu, Heat transfer in naturally ventilated rooms data from full-scale measurements, ASHRAE Transactions, (1984) 211-224.

[5] ISO, Moderate thermal environments - determination of the PMV and PPD indices and specifications for thermal comfort. International Standard 7730, 1993.

[6] G.O. Freskos, Influence of Various Factors on the Prediction Furnished by CFD in Cross-Ventilation Simulations. Roomvent (1998).

[7] Y. Lino, et al. Study on Airflow Characteristics in and Around Building Induced by Cross Ventilation using Wind Tunnel Experiment and CFD Simulation. Roomvent (1998).

[8] S. Murakami, et al, Examining the k- $\varepsilon$ model by means of a wind tunnel test and large eddy simulation of the turbulence structure around a cube, Journal of Wind Eng. And Industrial Aerodynamics, 41-44 (1990) 87-100.

[9] PHOENICS Version 3.1. CHAM Ltd., London, UK, 1998.

[10] V. Straaten, Thermal Performance of Buildings, Elsevier, Amsterdam, 1967.

[11] C. Allocca, S.D. Hamilton, J. Huang, N. Kobayashi, Z. Zhai, Q. Chen, Integration of indoor and outdoor airflow study for natural ventilation design using CFD, Proceedings of the 21st AIVC Annual Conference on Innovations in Ventilation Technology, The Hague, The Netherlands, 2000.

[12] R.M. Aynsley, A resistance approach to estimating airflow through buildings with large openings due to wind, ASHRAE Transactions (1988), 1661-1668.

[13] ASHRAE, ASHRAE Handbook Fundamentals SI Edition. ASHRAE Atlanta, 1997. 
[14] Panofsky H.A., Dutton J.A., Atmospheric Turbulence. John Wiley \& Sons (1984).

[15] Haghighat F., Rao J., Fazio P., The Influence of Turbulent Wind on Air Change Rates-a Modeling Approach. Building and Environment (1991) Vol.26 No.2, 95109.

[16] Etheridge D.W., Nolan J.A., Ventilation Measurements at Model Scale in a Turbulent Flow. Building and Environment (1979) Vol. 14, 53-64.

[17] A.F. Mills, Basic Heat and Mass Transfer. Irwin, Chicago,1995.

[18] G. Carrilho da Graça, Ventilative Cooling (M.Sc. Thesis). Massachusetts Institute of Technology, Cambridge, 1999. 
Table 1

Description of the cases studied

\begin{tabular}{|l|c|c|}
\hline \multirow{2}{*}{ Case } & \multicolumn{2}{|c|}{ Composition of the Partitions } \\
\cline { 2 - 3 } & Floor & Internal walls \\
\hline Reference & $100 \mathrm{~mm}$ concrete & $100 \mathrm{~mm}$ concrete, \\
\hline Night cooling & $100 \mathrm{~mm}$ concrete & $100 \mathrm{~mm}$ concrete \\
\hline Daytime Ventilation & $100 \mathrm{~mm}$ perforated concrete & Lightweight gypsum board \\
\hline
\end{tabular}

Table 2

Internal heat gains used in the study

\begin{tabular}{|c|c|c|c|}
\hline \multicolumn{2}{|c|}{ Lighting and Appliances } & \multicolumn{2}{|c|}{ Occupants } \\
\hline Day & Night & Day & Night \\
\hline $350 \mathrm{~W}$ & $175 \mathrm{~W}$ & $4 \times 85 \mathrm{~W}$ & $4 \times 85 \mathrm{~W}$ \\
\hline
\end{tabular}


Table 3

Important climatic parameters for Beijing and Shanghai

\begin{tabular}{|c|c|c|c|c|c|c|}
\hline \multirow{2}{*}{} & \multicolumn{5}{|c|}{ Days with Maximum Temperature Above $30^{\circ} \mathrm{C}$} \\
\cline { 2 - 7 } & $\begin{array}{c}\text { Number } \\
\text { of days }\end{array}$ & $\begin{array}{c}\text { Temperature } \\
\text { variation }\end{array}$ & $\begin{array}{c}\text { Average maximum } \\
\text { temperature and the } \\
\text { corresponding humidity }\end{array}$ & \multicolumn{2}{c|}{$\begin{array}{c}\text { Average wind } \\
\text { speed }\end{array}$} \\
\cline { 4 - 7 } & & & Temperature & RH (\%) & $\begin{array}{c}22: 00- \\
8: 00\end{array}$ & $\begin{array}{c}11: 00- \\
17: 00\end{array}$ \\
\hline Beijing & $41(27 \%)$ & $9.7 \mathrm{~K}$ & $32.8^{\circ} \mathrm{C}$ & $42 \%$ & $1.4 \mathrm{~m} / \mathrm{s}$ & $2.8 \mathrm{~m} / \mathrm{s}$ \\
\hline Shanghai & $55(36 \%)$ & $4.6 \mathrm{~K}$ & $32.9^{\circ} \mathrm{C}$ & $66 \%$ & $2.6 \mathrm{~m} / \mathrm{s}$ & $2.6 \mathrm{~m} / \mathrm{s}$ \\
\hline
\end{tabular}

The percentage of warm days refers to the period from May $1^{\text {st }}$ to September $30^{\text {th }}$. The temperature variation $\left(\mathrm{T}_{\mathrm{Var}}\right)$ is calculated by subtracting the lowest nighttime temperature $\left(\mathrm{T}_{\text {Low }}\right)$ to $30^{\circ} \mathrm{C}\left(\mathrm{T}_{\mathrm{Var}}=30-\mathrm{T}_{\text {Low }}\right)$. 


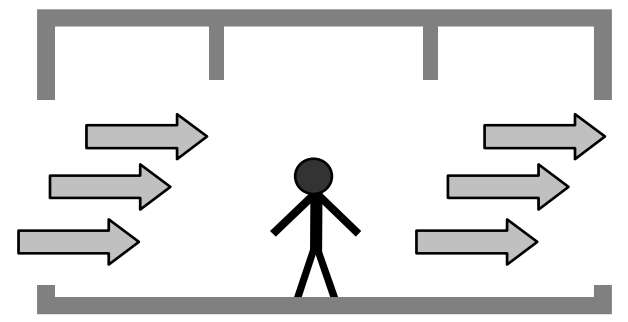

Airflow removes heat from the indoor environment

a

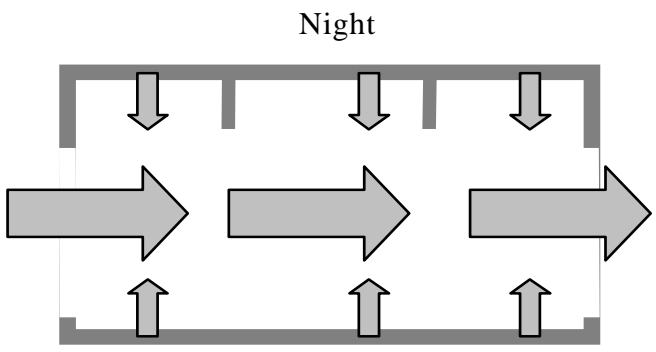

Walls Release Heat, Maximum Ventilation

$\mathbf{b}$

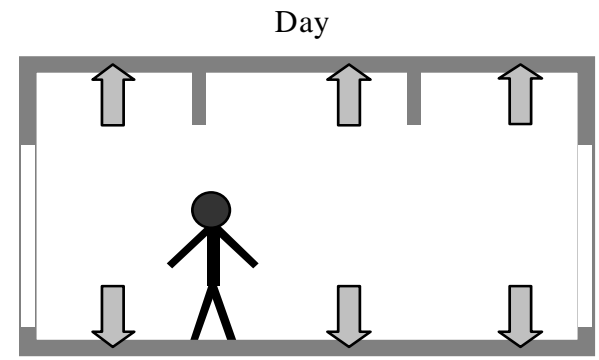

Walls absorb heat, minimum ventilation

c

Fig. 1. Principle of operation of the two ventilative cooling strategies: (a) daytime ventilation removes indoor heat by bringing in outdoor air, (b) night cooling cools the thermal mass during night, and (c) night cooling uses the thermal mass to absorb heat during the day. 

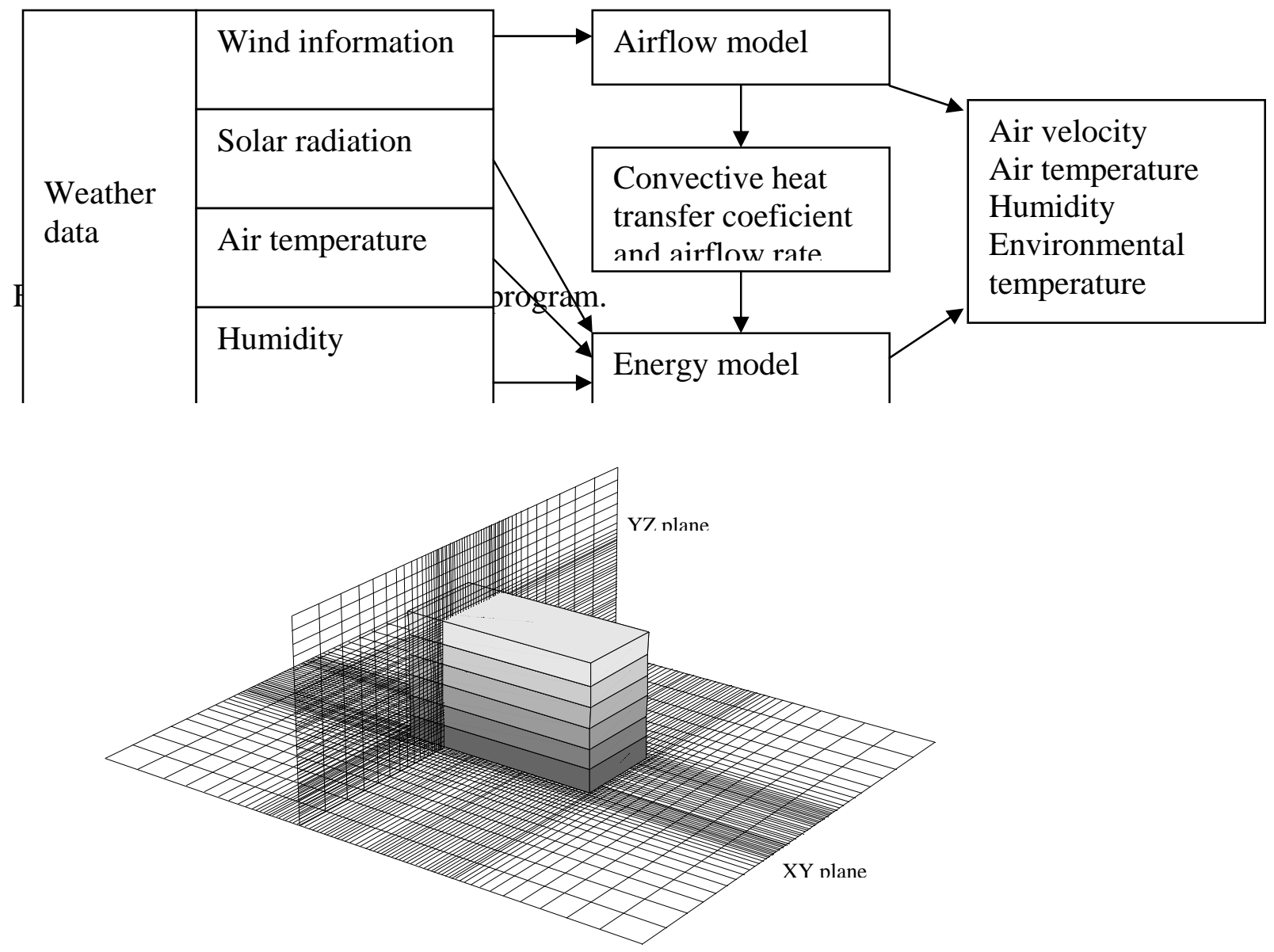


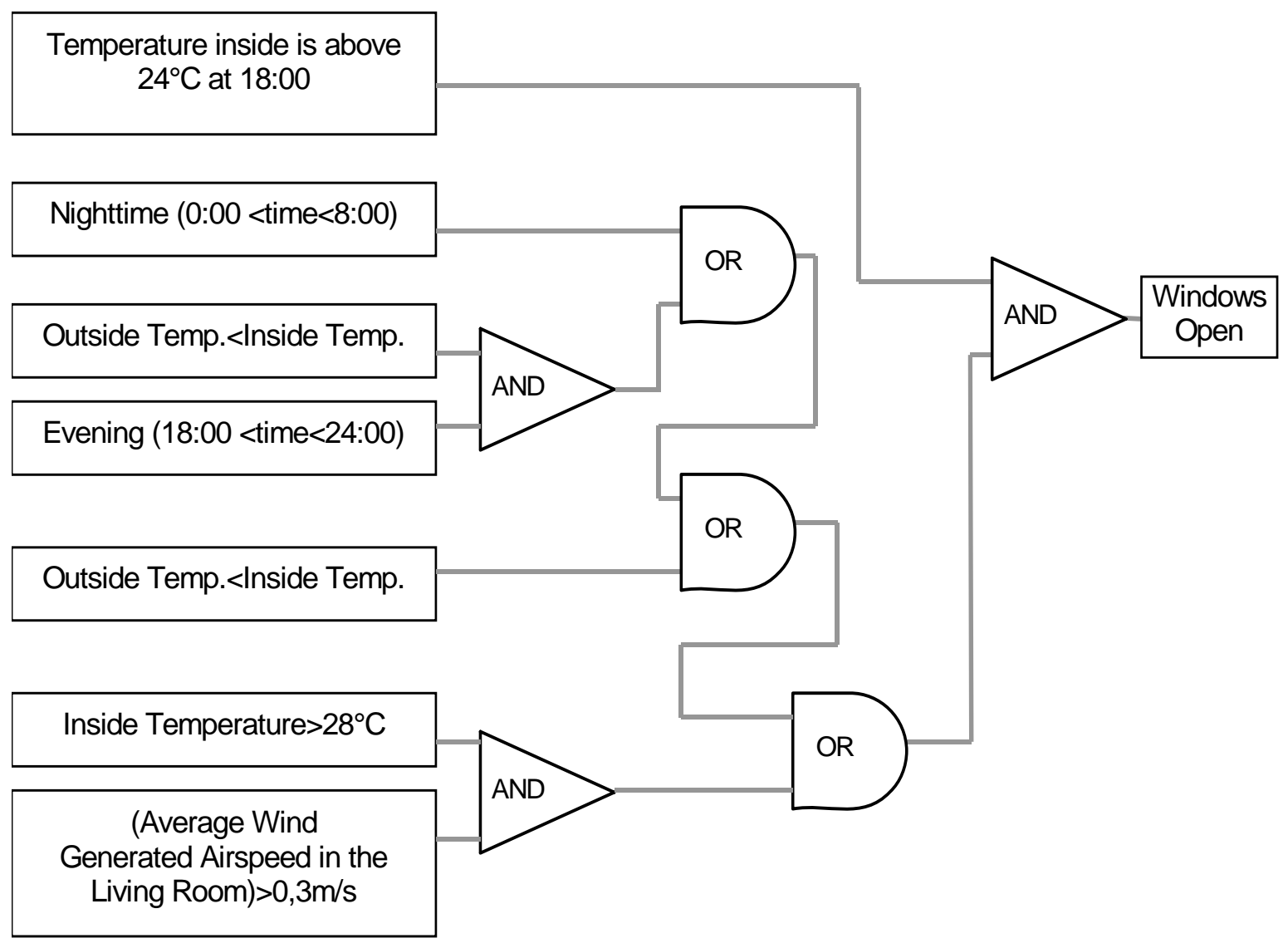

Fig. 4. Control system diagram for night cooling ventilation. 


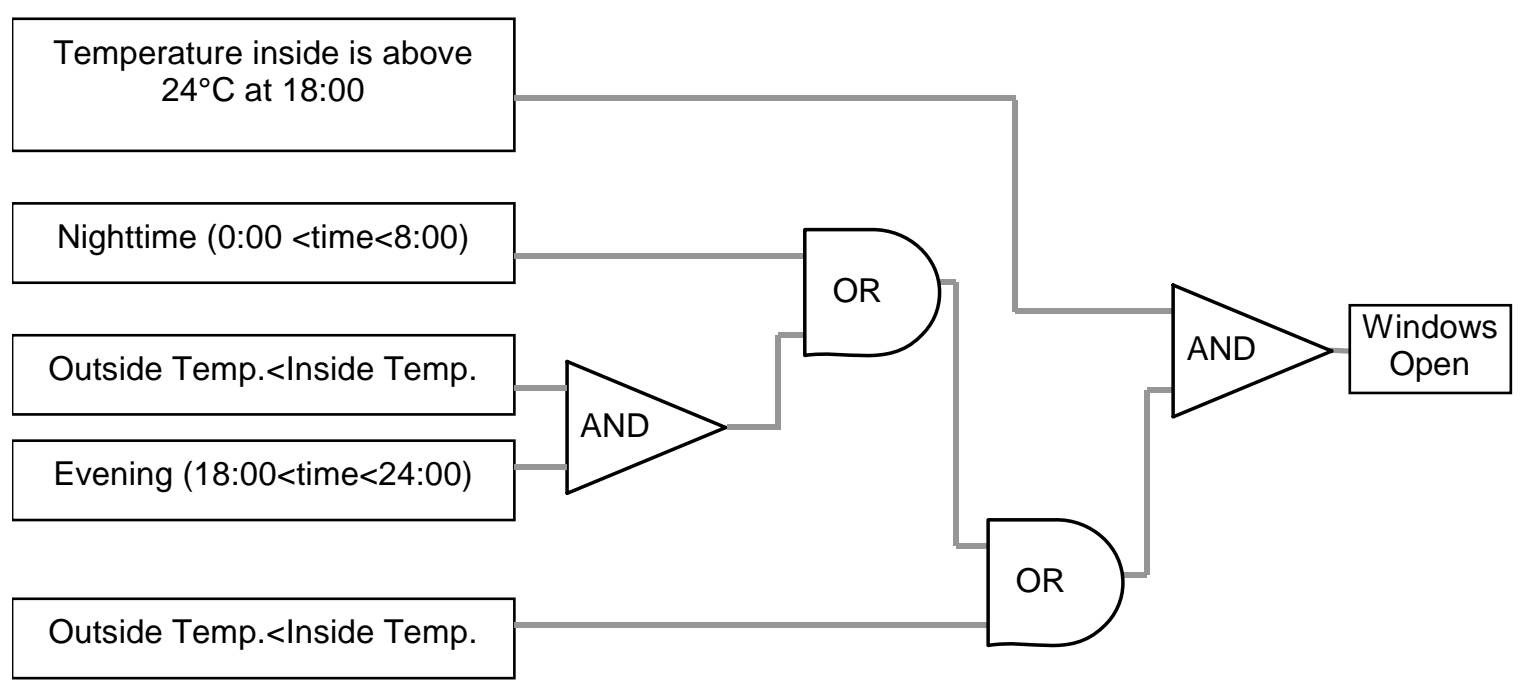

Fig. 5. Control system diagram for daytime comfort ventilation.

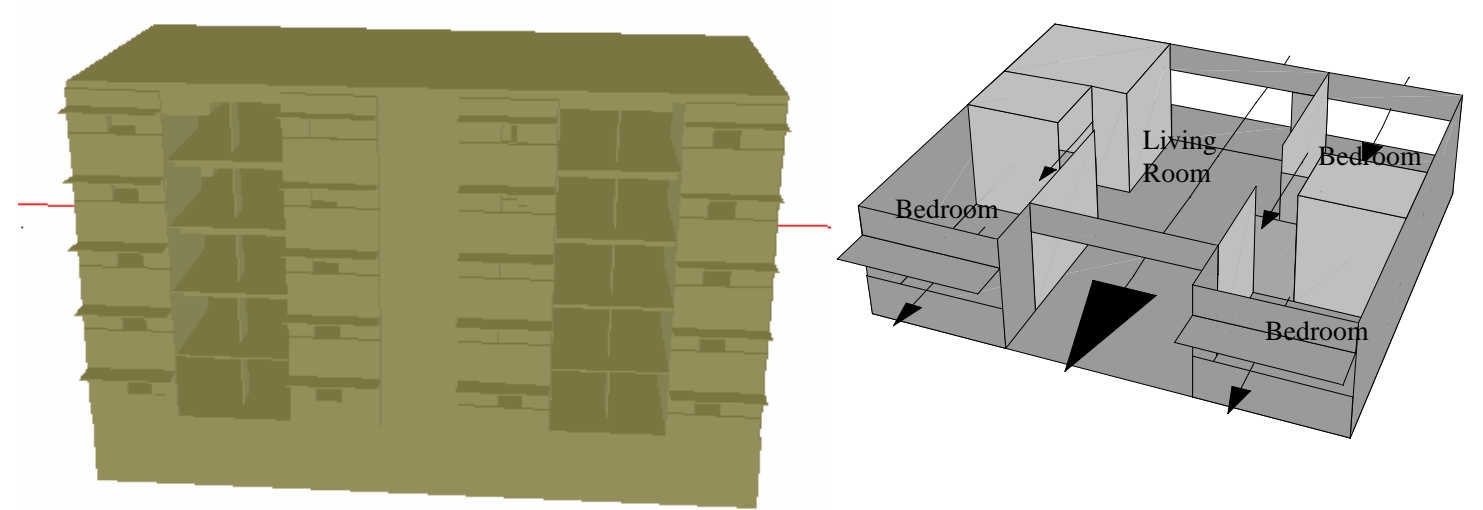

Fig. 6. The case studied: The left figure represents the six-story apartment building simulated, and the right figure shows the detailed layout of a unit in the building, the arrows represent the airflow direction for northern winds. 
Beijing, 24 hours

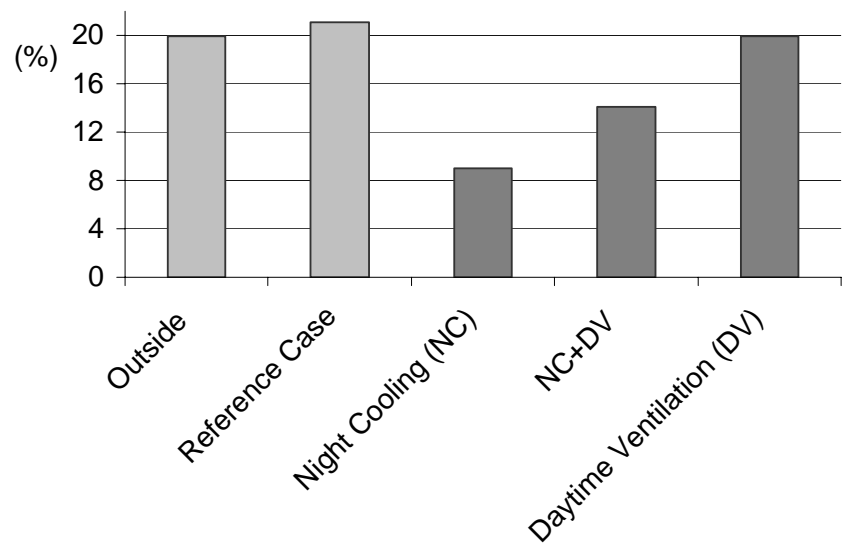

Beijing, 7:00-24:00

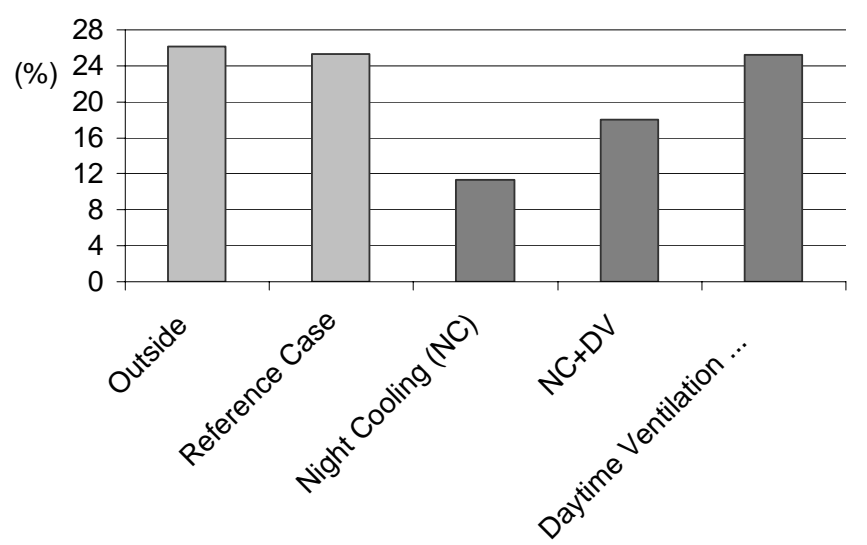

Fig.7. Percentage of discomfort hours using the two different cooling strategies in Beijing. 


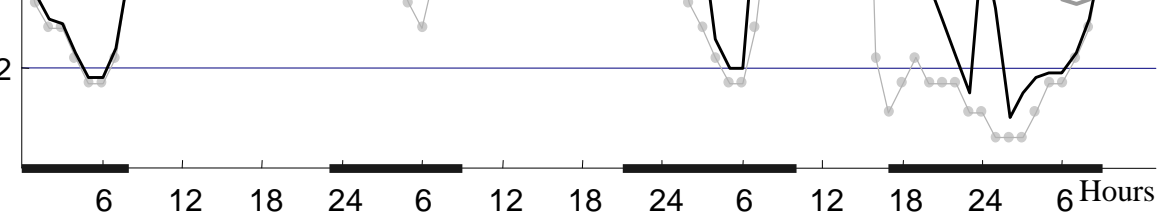

Fig. 8. Hourly temperature variation for Beijing, night cooling. Light Gray: Outside Temp. Medium Gray: Wall Temp. Black: Indoor Temp. The dark line in the horizontal axis indicates periods with fully open windows.

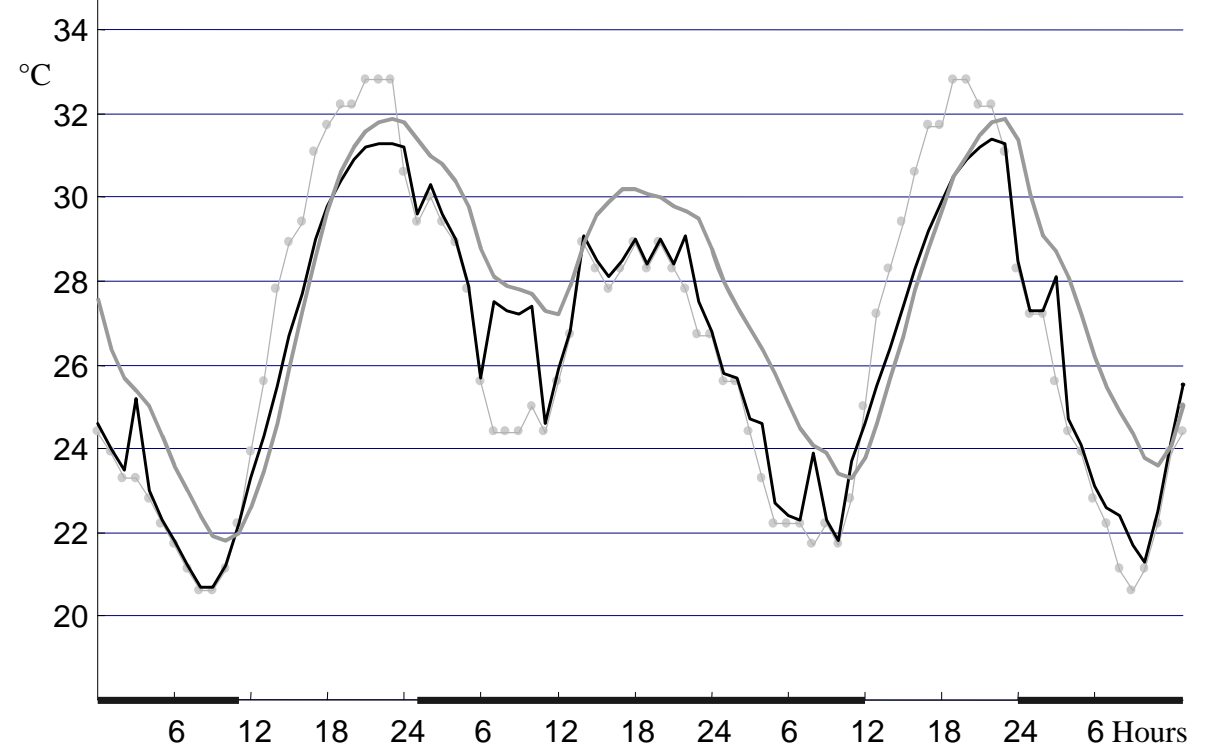

Fig. 9. Hourly temperature variation in Beijing, for daytime ventilation. Light gray: Outdoor air temperature, Medium gray: Wall temperature, Black: Indoor air temperature. The dark line in the horizontal axis indicates periods with fully open windows. 


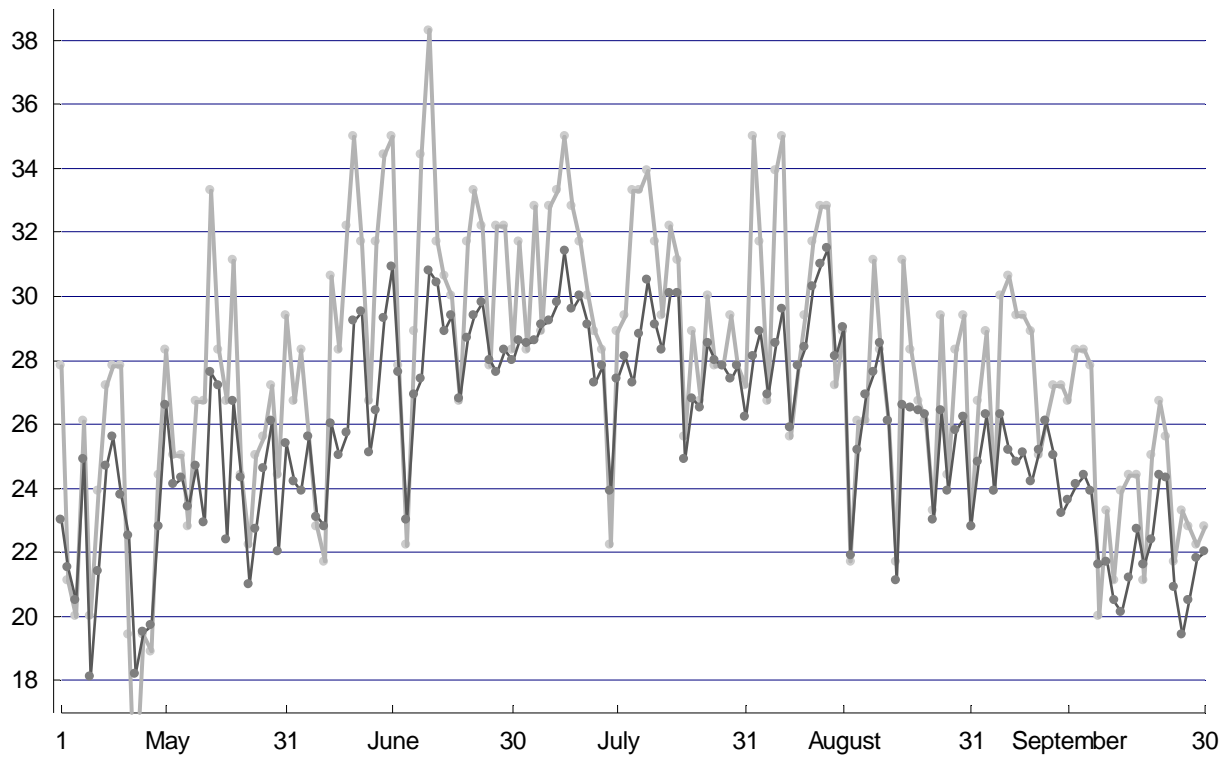

Fig. 10. Beijing: daily maximum air temperature $\left({ }^{\circ} \mathrm{C}\right)$ in a living room with the night cooling system (dark gray) and the outside (light gray).

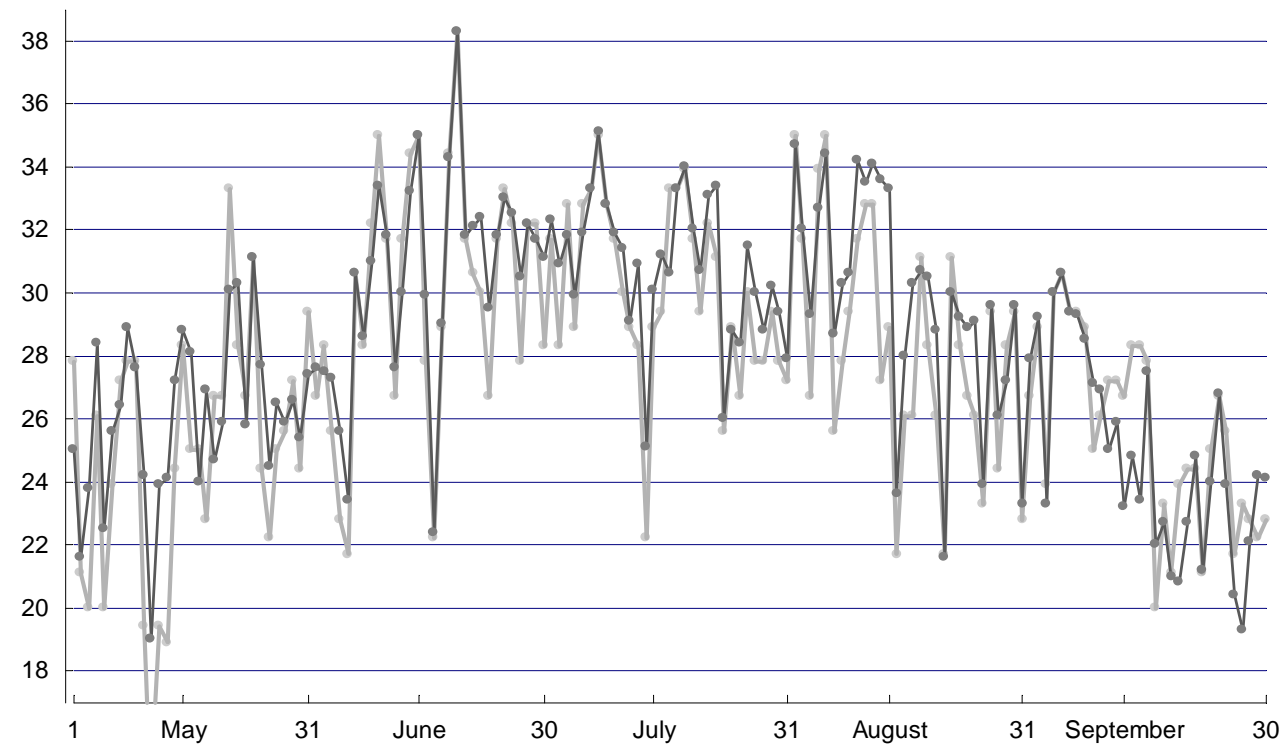

Fig. 11. Beijing: daily maximum temperature $\left({ }^{\circ} \mathrm{C}\right)$ in a living room with the daytime ventilation system (dark gray) and the outside (light gray). 
Shanghai, 24 hours

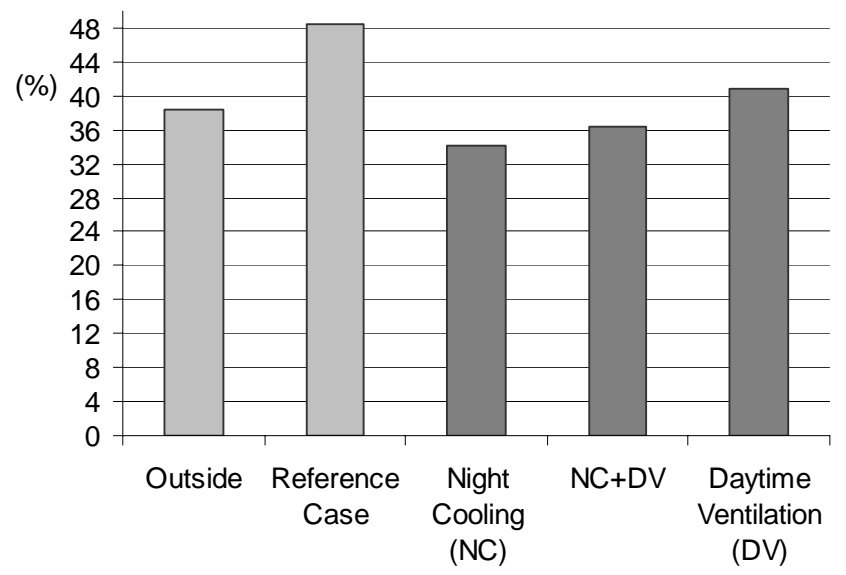

Shanghai, 7:00-24:00

(\%)
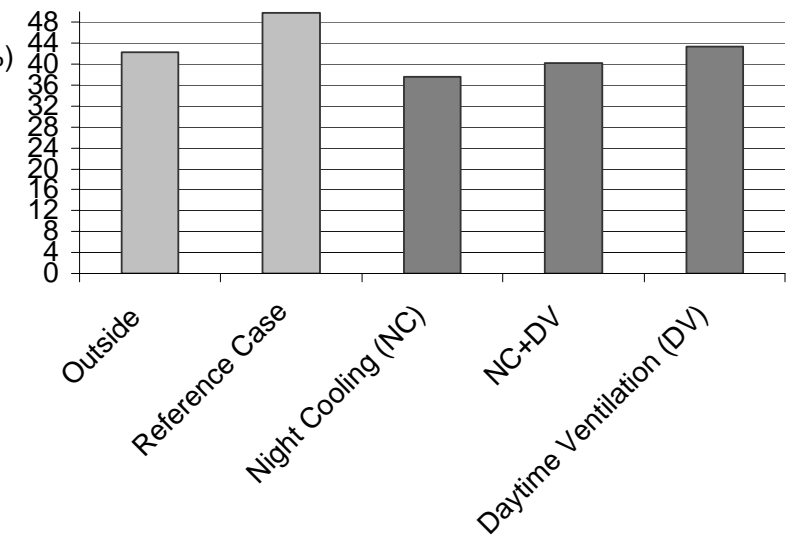

Fig. 12. Comparison of the discomfort hours using the different cooling strategies in Shanghai. 


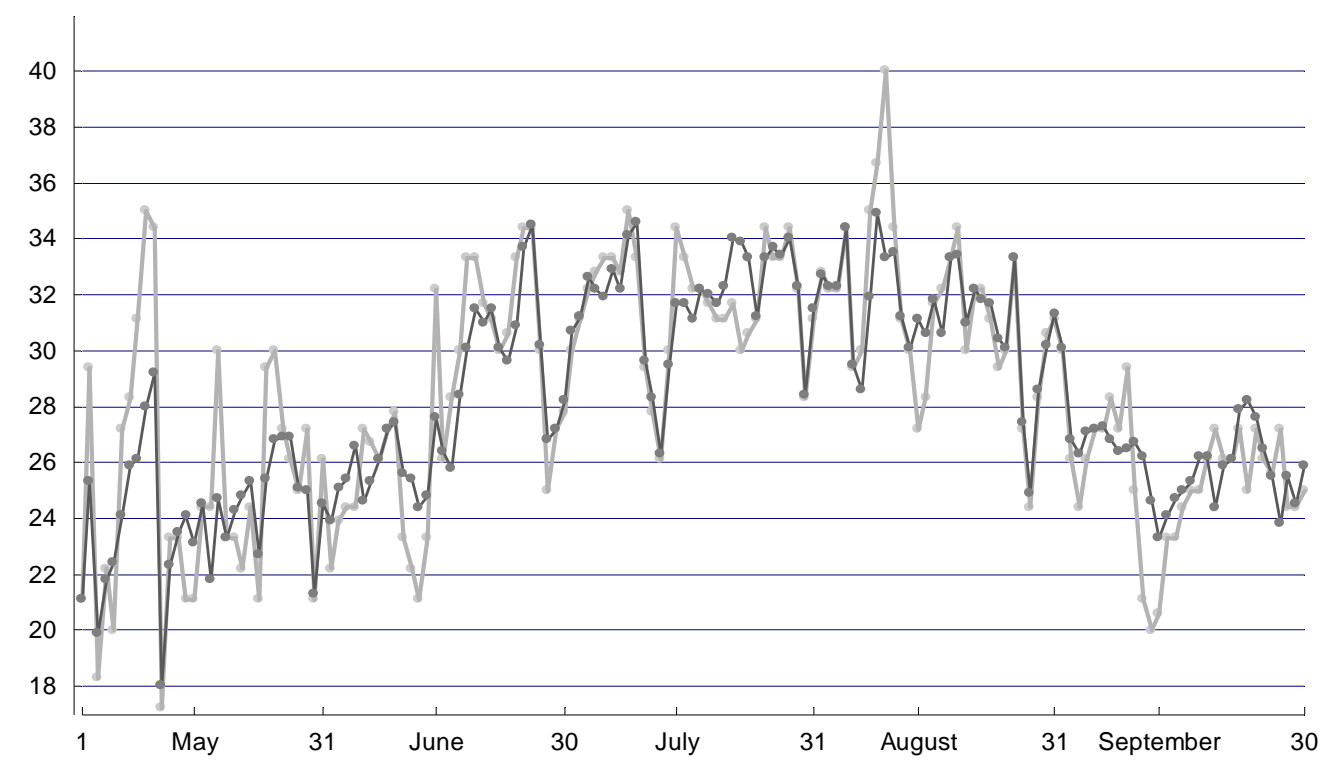

Fig. 13. Shanghai: daily maximum air temperature $\left({ }^{\circ} \mathrm{C}\right)$ in a living room with the night cooling system (dark gray) and the outside (light gray). 